Детекция генов приобретенных карбапенемаз у изолятов Acinetobacter baumannii, выделенных из гемокультуры больных опухолями системы крови Хрульнова С.А. ${ }^{1}$, Коробова А.Г. ${ }^{1}$ Фёдорова А.В. ${ }^{1}$, Фролова И.Н. ${ }^{1}$, Савочкина Ю.А. ${ }^{2}$, Клясова Г.А. ${ }^{1}$

1 ФГБУ «Национальный медицинский исследовательский центр гематологии» Минздрава России, Москва, Россия

2 ФБУН «Центральный научно-исследовательский институт эпидемиологии» Роспотребнадзора, Москва, Россия

Контактный адрес:

Светлана Алексеевна Хрульнова

Эл. почта: khrulnovas@mail.ru

Ключевые слова: Acinetobacter bаumannii, гемокультура, опухоли системы крови, карбапенемы, резистентность, ОХА-карбапенемазы.

\begin{abstract}
Цель. Изучить распространенность генов приобретенных карбапенемаз среди изолятов А. bаumannii, выделенных из гемокультуры больных опухолями системы крови.

Материалы и методы. В исследование были включены изоляты А. baumannii, выделенные из гемокультуры пациентов, находившихся на лечении в 7 стационарах России (2003-2015 гг.). Чувствительность изолятов $A$. baumannii к карбапенемам оценивали согласно критериям CLSI (2017). Наличие генов карбапенемаз класса D (групп blaохА-51, blaохА-24/40, blaохА-23 и blaохА-58) и класса B (групп bla IMp, blaviм и blandM) определяли методом ПЦР в режиме реального времени с использованием коммерческих наборов.

Результаты. Всего исследовано 74 изолята A. baumannii, выделенных из гемокультуры, из которых 55 (74,3\%) были нечувствительными к меропенему и/или имипенему. Гены приобретенных ОХА-карбапенемаз обнаружены у 70,9\% (39/55) карбапенемонечувствительных изолятов. Гены металло-бета-лактамаз (blandм, blaviм и blaimp) выявлены не были. Наиболее распространенными генами приобретенных ОХА-карбапенемаз были blaохА-24/40-like (51,3\%), далее следовали гены групп blaохА-23 $(38,5 \%)$ и blaохА-58 $(10,3 \%)$. Значения $М П K_{50 / 90}$ меропенема и имипенема оказались выше у изолятов A. baumannii, несущих гены приобретенных карбапенемаз, по сравнению с нечувствительными к карбапенемам изолятами без приобретенных карбапенемаз. Наиболее высокие значения $\mathrm{MПК}_{50 / 90}$ карбапенемов регистрировались у продуцентов ферментов группы ОХА-24/40 (64 и 128 мкг/мл).

Выводы. Гены приобретенных ОХА-карбапенемаз выявлены у 70,9\% карбапенемонечувствительных изолятов $A$. baumannii, среди которых преобладали продуценты ферментов группы ОХА-24/40, имеющие наиболее высокие значения МПК.
\end{abstract}

\title{
Detection of acquired carbapenemase genes among Acinetobacter baumannii isolated from blood culture in patients with hematological malignancies
}

\author{
Khrulnova S.A. ${ }^{1}$, Korobova A.G. ${ }^{1}$, Fyodorova A.V. ${ }^{1}$, Frolova I.N. ${ }^{1}$, Savochkina Yu.A. ${ }^{2}$, Klyasova G.A. \\ ${ }^{1}$ National Medical Research Center of Hematology, Moscow, Russia \\ ${ }^{2}$ Central Research Institute of Epidemiology, Moscow, Russia
}

Contacts:

Svetlana A. Khrulnova

E-mail: khrulnovas@mail.ru

Key words: Acinetobacter baumannii, blood culture, hematological malignancies, carbapenems, resistance, OXA-carbapenemases.
Objective. To evaluate the prevalence of acquired carbapenemase genes among $A$. baumannii isolates collected from blood culture in patients with hematological malignancies.

Materials and methods. This prospective multicenter study included A. baumannii isolated from blood culture in hematological patients in 7 Russian hospitals (2003-2015). Minimum inhibitory concentrations (MICs) of meropenem and imipenem were determined by broth microdilution method (CLSI, 2017). All A. baumannii isolates were tested by multiplex real-time PCR for presence of acquired carbapenemase genes (blaoxA-23-like, blaoXA-24/40-like, blaoxA-58-like, blandM-like, blavim-like and blaimP-like).

Results. A total of $74 \mathrm{~A}$. baumannii isolates were studied, of them $55(74.3 \%)$ were non-susceptible to meropenem and/or imipenem. Genes of acquired OXA-carbapenemases were detected in $70.9 \%(39 / 55)$ of carbapenem non-susceptible isolates. Metallo-beta-lactamase genes (blanDM-like, blavim-like and blaimp-like) were not detected. The most prevalent carbapenemase genes were blaoxA-24/40-like $(51.3 \%)$, followed by blaoxA-23-like $(38.5 \%)$ and blaoxA-58-like $(10.3 \%)$. The $\mathrm{MIC}_{50 / 90}$ values of meropenem and imipenem were higher in carbapenem non-susceptible $A$. baumannii harboring carbapenemase genes compared to isolates without acquired carbapenemase genes. A. baumannii isolates carrying blaoxA-24/40-like demonstrated the highest $\mathrm{MIC}_{50 / 90}$ values of carbapenems.

Conclusions. The majority of carbapenem non-susceptible $A$. baumannii isolates $(70.9 \%)$ carried acquired carbapenemase genes, of which blaoxA-24/40-like were predominant. The highest $M \mathrm{MC}_{50 / 90}$ values of carbapenems were detected in A. baumannii harboring blaoxA-24/40-like.

\section{Введение}

Acinetobacter baumannii относится к значимым нозокомиальным возбудителям, способным вызывать вспышки инфекций, особенно в отделениях реанимации и интенсивной терапии [1]. Согласно результатам ряда исследований, в России доля A. baumannii, выделенных из гемо- культуры больных опухолями системы крови, составляет 3-4\% [2-4]. По данным литературы, этот показатель варьируется от $2,9 \%$ до $6 \%[5,6]$, а у реципиентов гемопоэтических стволовых клеток достигает 11,8\% [7]. По результатам российского многоцентрового эпидемио- 
логического исследования антибиотикорезистентности возбудителей нозокомиальных инфекций «МАРАФОН», проведенного в 2013-2014 гг., в многопрофильных стационарах доля A. baumannii составила 13,7\% от всех выделенных бактериальных изолятов [8].

В настоящее время актуальной проблемой является распространение карбапенемонечувствительных A. baumannii. Высокая резистентность к карбапенемам отмечается и у изолятов, выделенных из гемокультуры больных опухолями системы крови. Так, согласно результатам российского исследования, у 66-69\% изолятов A. baumannii была выявлена нечувствительность к карбапенемам [4]. В исследовании, проведенном в Беларуси, доля карбапенеморезистентных изолятов среди A. baumannii, вызывающих инфекции кровотока у реципиентов гемопоэтических стволовых клеток, составила 75\% (12/16 изолятов) [7]. Кроме того, выделение резистентных к карбапенемам изолятов $A$. baumannii из гемокультуры являлось фактором риска летального исхода в течение 30 дней у больных опухолями системы крови [5, 7]. О высоком уровне устойчивости к карбапенемам сообщается также и у A. baumannii, выделенных в многопрофильных стационарах. По данным проспективного исследования (2008-2009 гг.), проведенного в 10 странах Азии, 67,3\% изолятов Acinetobacter spp., ставших причиной нозокомиальных пневмоний, оказались устойчивыми к имипенему [9]. Согласно данным Европейской системы по надзору за антибиотикорезистентностью (EARS-Net), в 2012-2015 гг. наиболее высокий уровень устойчивости к карбапенемам наблюдался в Греции, Хорватии и Румынии (81,5-93,5\%) [10]. Следует отметить, что во всем мире продолжает увеличиваться доля инфекций, вызванных карбапенемонечувствительными A. baumannii. По данным российского исследования «МАРАФОН», доля нечувствительных к карбапенемам $A$. baumannii за 7 лет увеличилась на 36-66\% [8]. По результатам анализа EARS-Net, в течение 4 лет наблюдений (2012-2015 гг.) наибольший прирост доли устойчивых к карбапенемам Acinetobacter spp. был зарегистрирован в Польше и на Кипре (на $27,4 \%$ и 26,6\% соответственно), а в Норвегии за тот же период частота детекции резистентных к карбапенемам изолятов увеличилась на 9,4\% при их полном отсутствии в 2012-2013 гг. [10]. В США доля устойчивых к карбапенемам изолятов выросла с 20,6\% (2002 г.) до $49,2 \%$ (2008 г.) [11].

Причины устойчивости к карбапенемам Acinetobacter spp. разнообразны и включают в себя изменение проницаемости наружной клеточной мембраны, эффлюкс, продукцию приобретенных карбапенемаз (металло-бета-лактамаз [МБЛ], ОХА-карбапенемаз), гиперпродукцию видоспецифических бета-лактамаз (ОХА-51 и родственных ферментов у $A$. baumannii) [1, 12, 13]. Наиболее значимым из известных механизмов резистентности к карбапенемам является продукция приобретенных карбапенемогидролизующих бета-лактамаз класса D (ОХА-карбапенемазы) и класса В (МБЛ).

Гены blaоха, кодирующие карбапенемазы A. baumannii, относят к 5 филогенетическим группам: blaохA-51-like, blaоxA-23-like, blaంxA-24/40-like, blaоxA-58-like и blaоxA-143-like [13]. Гены группы blaоха-51 являются видоспецифическими для A. baumannii, а групп blaоха-23-like, blaохА-24/40-like, blaоxA-58-like и blaоха-143-like - приобретенными. Видоспецифические гены blaохА-51-like экспрессируются слабо, но при определенных условиях экспрессия этих генов может увеличиваться, что приводит к гиперпродукции фермента и появлению устойчивости к карбапенемам у изолятов A. baumannii. Продукция приобретенных карбапенемаз групп ОХА-23, ОХА-24/40, ОХА-58 и ОХА-143 всегда обуславливает устойчивость к карбапенемам.

Целью данного исследования было изучить распространенность генов приобретенных карбапенемаз среди изолятов $A$. baumannii, выделенных из гемокультуры больных опухолями системы крови.

\section{Материалы и методы}

\section{Источники бактериальных изолятов}

Изоляты A. baumannii ( $=74$ ) были выделены из гемокультуры у пациентов, находившихся на лечении в гематологических отделениях 7 стационаров 6 городов России (Москва, Челябинск, Ростов-на-Дону, Иркутск, Новосибирск, Барнаул) в период с 2003 по 2015 гг. В исследование включали первый бактериальный изолят, выделенный из гемокультуры. Все включенные в исследование изоляты были доставлены в лабораторию ФГБУ «НМИЦ гематологии» Минздрава России, где проводились окончательная идентификация микроорганизмов, определение чувствительности к антимикробным препаратам (АМП) и детекция генов резистентности к карбапенемам.

\section{Видовая идентификация и хранение}

Видовую идентификацию полученных изолятов проводили в ФГБУ «НМИЦ гематологии» Минздрава России методом матричной лазерной десорбционной ионизационной времяпролетной масс-спектрометрии (MALDI-TOF MS) на анализаторе Microflex LT (Bruker Daltonics, Германия). Для идентификации полученных изолятов до вида брали изолированные колонии бактерий. Ионизацию бактериальных белков осуществляли с помощью специального реагента - матрицы ( $\alpha$-циано-4-гидроксикоричная кислота и раствор, содержащий 50\% ацетонитрила и 2,5\% трифторуксусной кислоты). Идентификацию проводили в автоматическом режиме с использованием программы MALDI Biotyper Real Time Classification, версия 3.1 (Bruker Daltonics, Германия). В качестве критерия надежной видовой идентификации использовали рекомендуемые значения коэффициента совпадения (Score) от 2,0 и выше. Видовую идентификацию изолятов A. baumannii дополнительно подтверждали с помощью детекции генов видоспецифических бета-лактамаз группы ОХА-51 методом полимеразной цепной реакцией (ПЦР) в режиме реального времени с использованием коммерческого набора «АмплиСенс ${ }^{\circledR}$ MDR Ab-OXA-FL» (ФБУН «Центральный НИИ эпидемиологии» Роспотребнадзора, Россия). Изоляты хранили при температуре $-70^{\circ} \mathrm{C}$ в триптиказо-соевом бульоне с добавлением 20\% глицерина.

Определение чувствительности к антибактериальным препаратам

Чувствительность к АМП исследовали методом последовательных микроразведений в бульоне в соответствии с рекомендациями CLSI, 2017 [14]. Категории чувствительности A. baumannii к меропенему и имипенему определяли на основании пограничных значений минимальных подавляющих концентраций (МПК), установленных CLSI (чувствительные $\leqslant 2$ мкг/мл, умеренно резистентные 
4 мкг/мл, резистентные $\geqslant 16$ мкг/мл). Термин «нечувствительные» изоляты объединял умеренно резистентные и резистентные к АМП микроорганизмы. Статистическую обработку и анализ результатов определения чувствительности проводили с помощью программы WHONET 5.6. Для внутреннего контроля качества определения чувствительности использовали референтные штаммы Escherichia coli ATCC ${ }^{\circledR} 25922$ и Pseudomonas aeruginosa ATCC 27853.

\section{Детекция генов карбапенемаз}

Выделение ДНК проводили с помощью коммерческого набора «ГК-Экспресс» (ФБУН «Центральный НИИ эпидемиологии» Роспотребнадзора, Россия). Наличие у $A$. baumannii генов карбапенемаз класса D (групп OXA-23, OXA-24/40 и ОХА-58) и класса В (групп IMP, VIM и NDM) определяли методом ПЦР в режиме реального времени с использованием коммерческих наборов «АмплиСенс ${ }^{\circledR}$ MDR Ab-OXA-FL» и «АмплиСенс ${ }^{\circledR}$ MDR MBL-FL» (ФБУН «Центральный НИИ эпидемиологии» Роспотребнадзора, Россия). Амплификацию проводили в термоциклере CFX96 Touch (Bio-Rad, CША).

\section{Результаты}

Всего исследовано 74 изолята A. baumannii, выделенных из гемокультуры больных опухолями системы крови. Из них $55(74,3 \%)$ изолятов были нечувствительными к меропенему и/или имипенему $(53$ (71,6\%) и 51 (68,9\%) изолятов соответственно). Частота обнаружения генов приобретенных OXА-карбапенемаз у всех A. baumannii составила 52,7\% (39/74 изолятов), а среди карбапенемонечувствительных изолятов - 70,9\% (39/55 изолятов). Гены МБЛ (blandм, blaviм и bla

Изоляты $A$. baumannii характеризовались высоким уровнем устойчивости к карбапенемам в течение всего анализируемого периода. В разные годы исследования доля карбапенемонечувствительных $A$. baumannii coставляла от $64,5 \%$ до 90,5\% (Рисунок 1). Несмотря на то что с 2003 по 2006 гг. у подавляющего большинства изолятов $(72,7 \%)$ была выявлена нечувствительность к карбапенемам, ни у одного из них не были обнаружены гены приобретенных карбапенемаз. Первые гены приобретенных ОХА-карбапенемаз были выявлены у карбапенемонечувствительных $A$. baumannii в 2007 г. Все последующие нечувствительные к карбапенемам A. baumannii, выделенные в 2007-2010 и 2011-2015 гг., содержали гены приобретенных карбапенемаз (Рисунок 1).

В Таблице 1 представлены данные по детекции генов приобретенных ОХА-карбапенемаз, которые были отнесены к 3 филогенетическим группам: blaохA-24/40-like, blaохA-23-like 1 blaохA-58-like. В геномах карбапенемонечувствительных изолятов с продукцией приобретенных

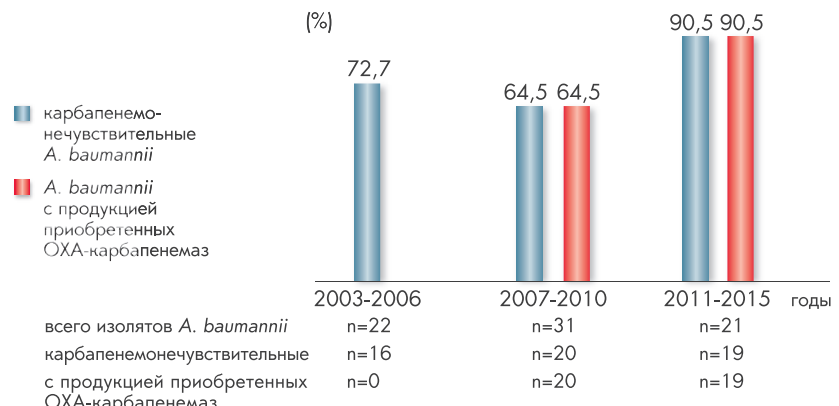

Рисунок 1. Распределение карбапенемонечувствительных изолятов $A$. baumannii в разные периоды исследования

OХА-карбапенемаз преобладали гены группы blaохА-24/40, выявленные у $20(51,3 \%)$ из 39 изолятов, далее следовали гены группы blaоха-23 $(38,5 \%)$ и blaоха-58 $(10,3 \%)$. В анализируемый период доля A. baumannii, несущих гены группы blaохА-24/40, увеличилась незначительно с 50\% (2007-2010 гг.) до 52,6\% (2011-2015 гг.), в то время как доля A. baumannii, содержащих гены группы blaоха-23, выросла с 30\% до 47,4\%. Гены группы blaоха-58 обнаружены только у $4(20 \%)$ изолятов A. baumannii, выделенных в 2007-2010 гг. (Таблица 1).

Значения $М П К_{50}$ и $М П К_{90}$ меропенема и имипенема у A. baumannii с продукцией приобретенных ОХА-карбапенемаз были выше значений $М П К_{50}$ и $М К_{90}$ этих антибиотиков среди карбапенемонечувствительных изолятов без продукции ОХА-карбапенемаз (Таблица 2). Значения МПК 50 меропенема составили 64 мкг/мл у изолятов-продуцентов приобретенных карбапенемаз против 16 мкг/мл у изолятов без продукции этих ферментов, а имипенема 32 против 4 мкг/мл соответственно. Наиболее высокие значения $M П K_{50}$ и $М П К_{90}$ карбапенемов определены у изолятов $A$. baumannii, несущих гены группы blaоха-24/40,

Таблица 2. Значения МПК меропенема и имипенема у A. baumannii, нечувствительных к карбапенемам $(\mathrm{n}=55)$

\begin{tabular}{|c|c|c|c|c|c|}
\hline \multirow{3}{*}{$\begin{array}{c}\text { Гены приобре- } \\
\text { тенных } \\
\text { ОХА- } \\
\text { карбапенемаз }\end{array}$} & \multirow{3}{*}{$\begin{array}{l}\text { Количество } \\
\text { изолятов, } \mathbf{n}\end{array}$} & \multicolumn{4}{|c|}{ Значения МПК (мкг/мл) } \\
\hline & & \multicolumn{2}{|c|}{ меропенем } & \multicolumn{2}{|c|}{ имипенем } \\
\hline & & $\mathrm{M} \Pi \mathrm{K}_{50}$ & МПК & $\mathrm{M \Pi K}_{50}$ & МПК \\
\hline Не выявлены & 16 & 16 & 32 & 4 & 16 \\
\hline Выявлены, & 39 & 64 & 128 & 32 & 128 \\
\hline $\begin{array}{l}\text { из них: } \\
\text { blaохА-24/40-like }\end{array}$ & 20 & 64 & 128 & 64 & 128 \\
\hline blaoxA-23-like & 15 & 16 & 64 & 16 & 64 \\
\hline blaoxA-58-like & 4 & 16 & 64 & 32 & 32 \\
\hline
\end{tabular}

Таблица 1. Распределение изолятов А. baumannii с продукцией приобретенных ОХА-карбапенемаз в разные периоды исследования

\begin{tabular}{|c|c|c|c|c|}
\hline \multirow{2}{*}{$\begin{array}{l}\text { Период исследования } \\
\text { (годы) }\end{array}$} & \multirow{2}{*}{$\begin{array}{c}\text { Число изолятов с приобретенными } \\
\text { ОХА-карбапенемазами, n }\end{array}$} & \multicolumn{3}{|c|}{$\begin{array}{c}\text { Число изолятов, содержащих гены приобретенных } \\
\text { ОХА-карбапенемаз, n (\%) }\end{array}$} \\
\hline & & blaoxA-24/40-like & blaoxA-23-like & blaoxA-58-like \\
\hline 2003-2006 & 0 & 0 & 0 & 0 \\
\hline 2007-2010 & 20 & $10(50)$ & $6(30)$ & $4(20)$ \\
\hline 2011-2015 & 19 & $10(52,6)$ & $9(47,4)$ & 0 \\
\hline Всего, n (\%) & 39 & $20(51,3)$ & $15(38,5)$ & $4(10,3)$ \\
\hline
\end{tabular}


и составили 64 и 128 мкг/мл соответственно. Значения $M П K_{50}$ и $М П К_{90}$ карбапенемов у изолятов, содержащих в своем геноме гены группы blaоха-23, были ниже и соответствовали 16 и 64 мкг/мл (Таблица 2).

\section{Обсуждение}

В проведенном нами исследовании нечувствительность к карбапенемам была выявлена у 74,3\% изолятов A. baumannii. По результатам ряда других исследований, посвященных изучению $A$. baumannii, выделенных из гемокультуры больных гемобластозами, доля карбапенемонечувствительных изолятов варьировала от $36,1 \%$ [5] до 100\% [6]. О различиях в уровне устойчивости к карбапенемам сообщалось и среди изолятов A. baumannii, выделенных в многопрофильных стационарах. Так, в Испании доля нечувствительных к карбапенемам изолятов $A$. baumannii, выделенных из гемокультуры, составила 84,75\% [15], а в Италии - 54\% [16].

Первыми ОХА-карбапенемазами, обнаруженными у A. baumannii, стали ферменты группы ОХА-23. Изолят A. baumannii, содержащий ген blaоха-23, выделили из гемокультуры больного в 1985 г. в Эдинбурге (Шотландия) [13]. В настоящее время в большинстве стран мира доминируют A. baumannii с продукцией ОХА-23-подобных карбапенемаз [17, 18]. Следующей охарактеризованной группой ОХА-карбапенемаз стали ферменты ОХА-24/40-подобные: изолят $A$. baumannii, несущий ген blaоха-24/40, выделили в Испании в 1997 г. [13]. Гены группы blaоха-24/40 чаще встречаются в геномах изолятов $A$. baumannii, выделенных в странах Пиренейского полуострова и Азии [18], и являются доминирующими среди карбапенемонечувствительных $A$. baumannii в России (39,7\%) [8]. В 2003 г. во Франции обнаружили изоляты A. baumannii, содержащие гены blaохА-58, которые принадлежали к новой группе ОХА-карбапенемаз ОХА-58-подобные [13]. В период с 1999 по 2009 гг. в ряде средиземноморских стран, в том числе в Италии, Греции, Ливане и Турции, среди устойчивых к карбапенемам A. baumannii преобладали изоляты, содержащие в своем геноме гены blaоxA-58 [20].

По результатам данного исследования, впервые гены приобретенных ОХА-карбапенемаз были обнаружены у A. baumannii в 2007 г. и относились к группе OXА-23подобных. Изоляты A. baumannii, выделенные в 20072010 гг., характеризовались разнообразием генов приобретенных ОХА-карбапенемаз (blaохА-24/40, blaоха-23 и b(аоха-58). Во всех анализируемых периодах преобладали изоляты A. baumannii, содержащие гены blaохA-24/40-like, что соотносится с данными других российских исследований, проведенных в многопрофильных стационарах. Так, согласно результатам исследования «МАРАФОН», доля A. baumannii с продукцией ОХА-24/40-подобных карбапенемаз составила 81, 1\% в 2011-2012 гг. и 62,5\% в 2013-2014 гг. [8, 21]. Гены группы blaоха-24/40 были обнаружены у 94,2\% изолятов $A$. baumannii, выделенных при раневой ожоговой инфекции [22]. Следует отметить, что в первых российских исследованиях («РЕЗОРТ» и «РЕВАНШ» в 2002-2004 и 2006-2008 гг.), включавших карбапенемонечувствительные A. baumannii с продукцией приобретенных ОХА-карбапенемаз, преобладали гены группы blaоха-58 (85\%), в то время как доля изолятов, несущих гены blaохА-23-like, составляла всего $15 \%$, а гены группы blaоха-24/40 Выявлены не были [12]. В проведенном нами исследовании доля $A$. baumannii, несущих гены blaоха-58, составила всего 10,3\%, и эти изоляты были выделены только в течение одного периода времени (2007-2010 гг.). Постепенное уменьшение доли A. baumannii с продукцией ОХА-58-подобных ферментов в России отмечено и в исследовании «МАРАФОН», по результатам которого в 2011-2012 гг. гены blaоха-58-like были обнаружены у 9\% изолятов с приобретенными ОХА-карбапенемазами, а в 2013-2014 гг. их доля составила только 0,9\% [8, 21]. Противоположная ситуация наблюдается с изолятами $A$. baumannii, coдержащими гены группы blaоха-23, процент которых в России постепенно растет. Так, в данном исследовании доля $A$. baumannii, содержащих гены группы blaоха-23, увеличилась с 30\% (2007-2010 гг.) до 47,4\% (20112015 гг.), в российском исследовании «МАРАФОН»с 9,9\% (2011-2012 гг.) до 36,6\% (2013-2014 гг.) $[8,21]$. Увеличение доли изолятов A. baumannii, coдержащих гены группы blaоха-23, отмечалось и в аналогичных зарубежных исследованиях. Так, в Италии в 2007 г. у A. baumannii преобладали гены группы blaохA-58-like (82,3\%), к 2011-2013 гг. частота их выявления уменьшилась до 4,5\% [16, 23], в то время как доля A. baumannii, содержащих гены группы blaоха-2з, увеличилась до 81,7-100\%. [16, 24]. Похожая картина наблюдалась также в Греции, где до 2009 г. преобладали A. baumannii, несущие гены группы blaохА-58, а в 20102011 гг. наибольшее распространение у $A$. baumannii получили гены blaоха-23-like $(72,4 \%)$, доля которых к 2015 г. увеличилась до 96,9\% [25, 26].

Было высказано предположение, что распространение ОХА-23-продуцирующих $A$. baumannii может быть связано с более высокой гидролитической активностью ферментов данной группы по сравнению с ОХА-58-подобными ферментами. Возможно, более высокие значения МПК карбапенемов у изолятов, содержащих гены blaоха-23-like, создают им преимущества для персистенции как в макроорганизме, так и в окружающей среде лечебных учреждений [25]. В данном исследовании наиболее высокие значения МПК карбапенемов имели изоляты $A$. baumannii с продукцией карбапенемаз группы ОХА-24/40. Учитывая тенденцию к увеличению доли изолятов, несущих гены группы blaохА-23-like, можно предположить, что в России доминирующим типом ОХА-карбапенемаз могут быть ОХА-23-подобные ферменты, вытеснив с лидирующей позиции ОХА-24/40подобные ферменты. Похожая ситуация наблюдалась в Португалии, где в начале 2000-х гг. большинство карбапенемонечувствительных изолятов A. baumannii несли гены группы blaохА-24/40, а уже в 2004-2008 гг. преобладали изоляты, содержащие гены blaохA-23-like (63,4\%) [27].

\section{Заключение}

Среди исследованных $A$. baumannii, выделенных из гемокультуры больных опухолями системы крови, преобладали карбапенемонечувствительные изоляты (74,3\%), из которых 70,9\% содержали в своем геноме гены приобретенных ОХА-карбапенемаз. Наиболее распространенными генами были blaохA-24/40-like (51,3\%). У изолятов $A$. baumannii с продукцией карбапенемаз группы ОХА-24/40 регистрировались более высокие значения МПК щими гены blaоха-23-like. 


\section{Литература}

1. Peleg A.Y., Seifert H., Paterson D.L. Acinetobacter baumannii: emergence of a successful pathogen. Clin Microbiol Rev. 2008;21(3):538-582. DOI: 10.1128/CMR.00058-07

2. Klyasova G.A., Speranskaya L.L., Mironova A.V., et al. The pathogens causing sepsis in immunocompromized patients: structure and problems of antibiotic resistance. Results of a multi-center cooperative study. Gematologiya i transfuziologiya. 2007;52(1):13-18. Russian. (Клясова Г.А., Сперанская Л.Л., Миронова А.В. и соавт. Возбудители сепсиса у иммунокомпрометированных больных: структура и проблемы антибиотикорезистентности (результать многоцентрового исследования). Гематология и трансфузеология. 2007;52(1):13-18.).

3. Klyasova G.A. Antimicrobial therapy. In: Savchenko V.G., ed. Program treatment of blood system diseases. Moscow: Praktika; 2012. p. 827 53. Russian. (Клясова Г.А. Антимикробная терапия. Под редакцией Савченко В.Г. Программное лечение заболеваний системы крови. Москва: Практика; 2012. с. 827-853.).

4. Klyasova G.A. Okhmat V.A. Antimicrobial therapy. In: Savchenko V.G., ed. Algorithms of diagnosing and protocols of treatment of blood system diseases. Moscow: Praktika; 2018. P. 1069-1113. Russian. (Клясова Г.А. Охмат В.А. Антимикробная терапия. Под редакцией Савченко В.Г. Алгоритмы диагностики и протоколы лечения заболеваний системы крови. Москва: Практика; 2018. с. 1067-1113.).

5. Wang X., Zhang L., Sun A., et al. Acinetobacter baumannii bacteraemia in patients with haematological malignancy: a multicenter retrospective study from the Infection Working Party of Jiangsu Society of Hematology. Eur J Clin Microbiol Infect Dis. 2017;36(7):10731081. DOI: 10.1007/s10096-016-2895-2

6. Gedik H., Simșek F., Kantürk A., et al. Bloodstream infections in patients with hematological malignancies: which is more fatal cancer or resistant pathogens? Ther Clin Risk Manag. 2014;10:743752. DOI: $10.2147 /$ TCRM.S68450

7. Stoma I., Karpov I., Milanovich N., Uss A., Iskrov I. Risk factors for mortality in patients with bloodstream infections during the preengraftment period after hematopoietic stem cell transplantation. Blood Res. 2016;51(2):102-106. DOI: 10.2147/TCRM. S68450

8. Sukhorukova M.V., Edelstein M.V., Skleenova E.Yu., et al. Antimicrobal resistance of nosocomial Acinetobacter spp. isolates in Russia: results of multicenter epidemiological study «MARATHON» 20132014. Klinicheskaja mikrobiologija i antimikrobnaja himioterapija. 2017;19(1):42-47. Russian. (Сухорукова М.В., Эйдельштейн М.B., Склеенова Е.Ю. и соавт. Антибиотикорезистентность нозокомиальных штаммов Acinetobacter spp. в стационарах России: результаты многоцентрового эпидемиологического исследования «МАРАФОН» в 2013-2014 гг. Клиническая микробиология и антимикробная химиотерапия. 2017;19(1):42-47.).

9. Chung D.R., Song J.H., Kim S.H., et al. High prevalence of multidrugresistant nonfermenters in hospital-acquired pneumonia in Asia. Am J Respir Crit Care Med. 2011;184:1409-1417. DOI: 10.1164/ rccm.201102-03490C

10. European Centre for Disease Prevention and Control. Antimicrobial resistance surveillance in Europe 2015. Annual Report of the European Antimicrobial Resistance Surveillance Network (EARS-Net). Stockholm: ECDC; 2017. Available at: https://ecdc.europa.eu/en/ publications-data/surveillance-antimicrobial-resistance-europe-2017.

11. Mera R.M., Miller L.A., Amrine-Madsen H., Sahm D.F. Acinetobacter baumannii 2002-2008: increase of carbapenem-associated multiclass resistance in the United States. Microb Drug Resist. 2010;16:209215. DOI: $10.1089 / \mathrm{mdr} .2010 .0052$

12. Martinovich A.A. Resistance Trends and Epidemiology of Acinetobacter Infections in Russia. Klinicheskaja mikrobiologija i antimikrobnaja himioterapija. 2010;12(2):96-105. Russian. (Мартинович A.A. Динамика антибиотикорезистентности и эпидемиология инфекций, вызванных Acinetobacter spp., в России. Клиническая микробиология и антимикробная химиотерапия. 2010;12(2):96-105.).

13. Evans B.A., Amyes S.G. OXA $\beta$-lactamases. Clin Microbiol Rev. 2014;27:241-263. DOI: 10.1128/CMR.00117-13

14. Clinical and Laboratory Standards Institute. Performance Standards for Antimicrobial Susceptibility Testing; Twenty-Seventh Informational Supplement. CLSI document M100-S27. Wayne, PA: Clinical and Laboratory Standarts Institute; 2017.

15. Dahdouh E., Gómez-Gil R., Pacho S., et.al. Clonality, virulence determinants, and profiles of resistance of clinical Acinetobacter baumannii isolates obtained from a Spanish hospital. PLoS One. 2017;12(4):e0176824. DOI: 10.1371/journal.pone.0176824

16. Principe L., Piazza A., Giani T., et al. Epidemic diffusion of OXA-23-producing Acinetobacter baumannii isolates in Italy: results of the first cross-sectional countrywide survey. J Clin Microbiol. 2014;52(8):3004-3010. DOI: 10.1128/JCM.00291-14

17. Mugnier P.D., Poirel L., Naas T., Nordmann P. Worldwide dissemination of the blaoxA-23 carbapenemase gene of Acinetobacter baumannii. Emerg Infect Dis. 2010;16(1):35-40. DOI: 10.3201/ eid1601.090852

18. Viana G.F., Zago M.C., Moreira R.R., et al. ISAba1/bla: a serious obstacle to controlling the spread and treatment of Acinetobacter baumannii strains. Am J Infect Control. 2016;44:593-595. DOI: 10.1016/j.ajic.2015.11.020

19. Zarrilli R., Giannouli M., Tomasone F., Triassi M., Tsakris A. Carbapenem resistance in Acinetobacter baumannii: the molecular epidemic features of an emerging problem in health care facilities. J Infect Dev Ctries. 2009;3:481-489.

20. Di Popolo A., Giannouli M., Triassi M., Brisse S., Zarrilli R. Molecular epidemiological investigation of multidrug-resistant Acinetobacter baumannii strains in four Mediterranean countries with a multilocus sequence typing scheme. Clin Microbiol Infect. 2011;17(2):197201. DOI: $10.1111 /$ j.1469-0691.2010.03254.x

21. Sukhorukova M.V., Edelstein M.V., Skleenova E.Yu., et al. Antimicrobal resistance of nosocomial Acinetobacter spp. isolates in Russia: results of multicenter epidemiological study «MARATHON» 2011-2012. Klinicheskaja mikrobiologija i antimikrobnaja himioterapija. 2014; 16 (4):266-272. Russian. (Сухорукова М.В., Эйдельштейн М.B., Склеенова Е.Ю. и соавт. Антибиотикорезистентность нозокомиальных штаммов Acinetobacter spp. в стационарах России: peзультаты многоцентрового эпидемиологического исследования «МАРАФОН» в 2011-2012 гг. Клиническая микробиология и антимикробная химиотерапия. 2014;16(4):266-272.)

22. Gordinskaya N.A., Sabirova E.V., Abramova N.V., Karaseva G.N., Nekaeva E.S. Antibiotics sensitivity and molecular mechanisms of resistance of Acinetobacter baumanii, infectious agents of burnwound infection. Medicinskij almanah. 2015;5(40):99-101. Russian. (Гординская Н.А., Сабирова Е.В., Абрамова Н.В., Карасева Г.Н., Некаева Е.С. Антибиотикочувствительность и молекулярные механизмы резистентности Acinetobacter baumanii, возбудителей раневой ожоговой инфекции. Медицинский альманах. 2015;5(40):99-101.).

23. Migliavacca R., Espinal P., Principe L., et al. Characterization of resistance mechanisms and genetic relatedness of carbapenemresistant Acinetobacter baumannii isolated from blood, Italy. Diagn Microbiol Infect Dis. 2013;75(2):180-186. DOI: 10.1016/j. diagmicrobio.2012.11.002

24. Mezzatesta M.L., Caio C., Gona F., et al. Carbapenem and multidrug resistance in Gram-negative bacteria in a single centre in Italy: considerations on in vitro assay of active drugs. Int J Antimicrob Agents. 2014;44:112-116. DOI: 10.1016/j.ijantimicag.2014.04.014

25. Liakopoulos A., Miriagou V., Katsifas E.A., et al. Identification of OXA-23-producing Acinetobacter baumannii in Greece, 2010 to 2011. Euro Surveill. 2012;17(11). pii: 20117.

26. Pournaras S., Dafopoulou K., Del Franco M., et al. Predominance of international clone 2 OXA-23-producing-Acinetobacter baumannii clinical isolates in Greece, 2015: results of a nationwide study. Int J Antimicrob Agents. 2017;49(6):749-753. DOI: 10.1016/j. ijantimicag.2017.01.028

27. Grosso F., Quinteira S., Peixe L. Understanding the dynamics of imipenem-resistant Acinetobacter baumannii lineages within Portugal. Clin Microbiol Infect. 2011;17(8):1275-1279. DOI: $10.1111 /$ j.1469-0691.2011.03469.x 